\title{
A Proof of Euclid's SAS (side angle side) Theorem of Congruence of Triangles via the Cross Section of a Double Cone.
}

\author{
Michael. C. Dokai \\ B.Sc. (Hons.), M.Sc. M.Ed, PGD. 5, Oredola Street, Somolu, Lagos
}

\begin{abstract}
The aim of this research is to find a proof of the elusive side angle side (SAS) theorem of Euclid on the congruence of triangles using the cross section of a double cone. It is known that the SAS theorem has remained analytically unproved for over 2000 years. The method used for over 2000 years for proving this very important side angle side (SAS) theorem of Euclid has been the method of superposition whereby two triangles are tested for congruence by applying one to the other.
\end{abstract}

\section{Introduction}

At the end of his proof of this side angle side theorem by the method of superposition, P. Abbott in his 'Teach Yourself Geometry' (1988), pointed out that modern mathematicians have raised objections to this as a method of proof. He continued by stating, "However, no other satisfactory method of proving this theorem has been evolved."

This researcher decided to take up the challenge to find out why and, if possible devise a proof. P. Abbott had written books on geometry, Trigonometry, Algebra and Calculus and was for sometime the Honourable Secretary of the Teaching Committee of the Mathematical Association in UK.

Side Angle Side (SAS)

\section{Brief History}

History has it that a great Greek geometer and wealthy merchant by the name of Thales of Miletus (Ca.640 to Ca.546BC) was asked to solve a surveying problem. He was asked to determine the distance between two points, A and B which were separated by a lake fig.(i).

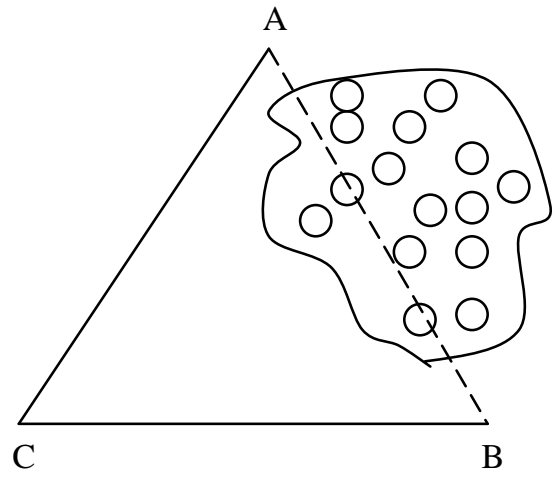

Fig (i)

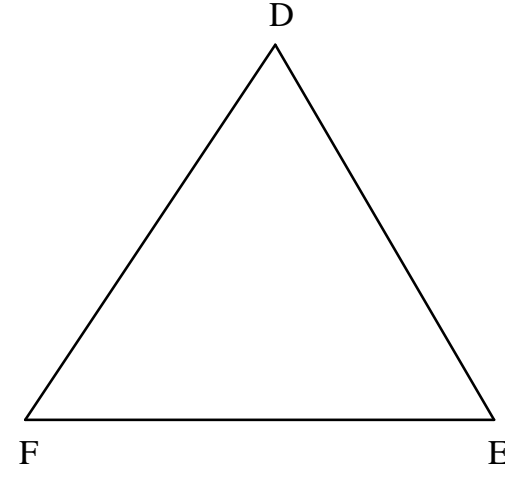

Fig (ii)

In order to achieve this purpose, Thales took a third point $\mathrm{C}$ outside the lake from where he measured the distances $\mathrm{CA}$ and $\mathrm{CB}$ and, also, the angle ACB. Then he moved to a space outside the lake and constructed the triangle $\mathrm{DEF}$ such that $\mathrm{FD}=\mathrm{CA}, \mathrm{FE}=\mathrm{CB}$ and angle $\mathrm{DFE}=$ angle $\mathrm{ACB}$ fig (ii). He then came to the conclusion that the triangles $\mathrm{ABC}, \mathrm{DEF}$ were equal in all respects and therefore that $\mathrm{AB}=\mathrm{DE}$.

His conclusion followed from the fact that superimposing $\triangle \mathrm{DFE}$ on $\triangle \mathrm{ABC}$ would give exact fit of the two triangles. This method of using the equality of a pair of sides and the included angles to show that two triangles were congruent became known as SAS (side angle side).

\section{Pythagoras Theorem}

A well known and significant theorem in mathematics is known as the Pythagoras Theorem which is attributed to a Greek who existed about the same period as Thales. The theorem of Pythagoras is said to be the most important geometrical discovery of the ancient Greek world. The theorem states that 'the square on the hypotenuse of a right-angled triangle is equal to the sum of the squares on the other two sides'. 
The method of proof of this theorem by Pythagoras is not generally known. But 200 years after Pythagoras, another great Greek geometer by the name of Euclid (Ca. 300 BC) gave an analytical proof of Pythagoras theorem by repeatedly using SAS theorem which he propounded as a theorem. Euclid who propounded the SAS (side angle side) method earlier used by Thales as a theorem also repeatedly used it in his proof that the base angles of an isosceles triangle are equal. It is said that this was the first 'difficult' theorem in Euclid. The difficulty follows from the fact that pupils generally found it difficult to follow his method of proof due to the form of the figure used by Euclid. Hence the figure is referred to as pons asinorum or the bridge of fools. Some authors call it the Bridge of Assess. See fig (iii).

The proof using the figure entails juggling of congruent triangles. Euclid used the SAS theorem to prove many other theorems

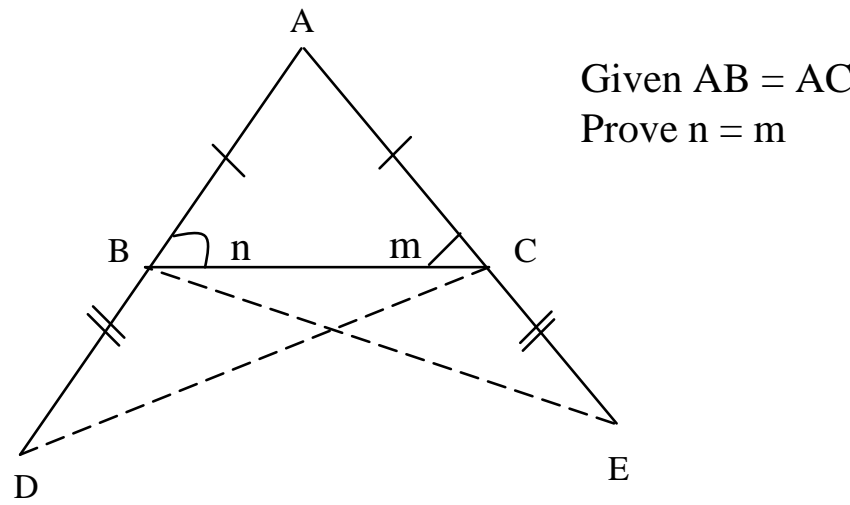

Fig (iii)

in geometry contained in his famous books known as Euclid's Elements. However of concern to us here is that this important SAS theorem was not proved analytically by Euclid. He proved it by the method of superposition, a method that modern mathematicians now question. Indeed it is believed by modern mathematicians that there are some hidden assumptions in some of the Greek proofs. Finding or devising an analytical proof of this first theorem of congruence, the SAS will accord it legitimacy and fill a gap in the annals of mathematics.

This researcher decided to take up the challenge of finding the secret, if it is hidden, and/or devise a satisfactory proof of the theorem.

\section{The Search for a Proof}

Euclid was believed to be the founder of the Alexandrian Mathematical School (Cosmopolitan University of Alexandria). He systematized Greek geometry and is the most famous of the masters of geometry. This researcher believes that since Euclid propounded the SAS method of congruence of two triangles as a theorem and not as an axiom, therefore there must be an analytical proof.

For over 2000 years the SAS theorem was proved by the method of superposition to establish the congruence of two triangles by superimposing one triangle on the other. The search for an analytical proof involved digging deep into past literature on the beginnings of geometry including the masterpiece, Euclid's Elements. Modern books were found to be virtually unhelpful as mere definitions were used in defining what constituted congruence of two triangles without giving any analytical proofs, a procedure so important for having deeper and clearer understanding of logical procedures and encouraging mastery of any subject.

However, the search into the past yielded an important and probably little noticed fact, an axiom long laid down by the Greeks. It is the axiom of movement of geometric figures.

Axiom: Any geometric figure may be moved from one place to another without changing its size or shape.

This fact that it was permissible to move a geometric figure from one place to another appeared to explain why the method of superposition had been used over the years to prove the SAS theorem. Armed with it, the researcher decided to carry out some experiments by juggling with a pair of C-Caution used when a vehicle breaks down for warning on coming motorists.

\section{The Experiment}

A pair of C-Caution (as it is known in Nigeria) was acquired. A pair of C-caution is a pair of identical triangles with reflective faces that could be made to stand, one in front and the other at the back of a broken down vehicle, as a warning to on coming motorists.

Each of the two triangles was marked on both sides with the data of the theorem, fig (iii). 


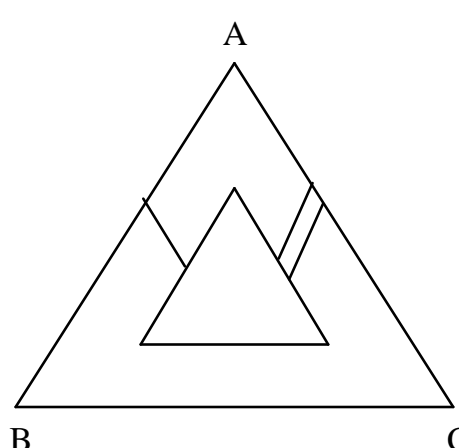

B
C Fig (iii)

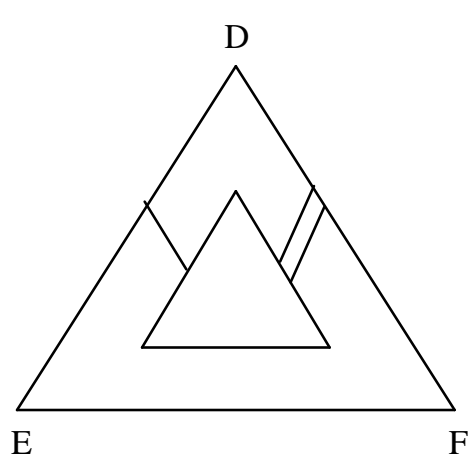

The two triangles now represent (physically) the triangles given on paper. The experiment started with the usual method of superimposing one triangle on the other. Clearly what is in doubt is whether.

$$
\mathrm{BC}=\mathrm{EF} \text {. }
$$

Therefore the theorem would be proved if it can be shown that: $\mathrm{BC}=\mathrm{EF}$.

From the researchers knowledge and experience it was felt that there must be a way to link the two sides $\mathrm{BC}$ and $\mathrm{EF}$ in order to formulate a model (perhaps in form of an equation) that could be manipulated to show that $\mathrm{BC}=\mathrm{EF}$.

It was clear that there was a need to move away from just superimposing one triangle on the other and stopping there. Taking advantage of the axiom of movement of geometric figures quoted earlier, this researcher tried moving around the two triangles, always starting with superimposing one on the other. One day, after starting by superimposing triangle $\mathrm{DEF}$ on triangle $\mathrm{ABC}$, the researcher flipped triangle $\mathrm{DEF}$ over triangle $\mathrm{ABC}$ and obtained what is in fig (iv).

This was good because, $<\mathrm{A}=<\mathrm{D}$ (given) and since they are vertically opposite angles, therefore BF, EC are straight lines. This meant that $\mathrm{BC}, \mathrm{EF}$ have been linked by straight lines BF, EC. But the pattern of the figure did not yield a method of proof to show that $\mathrm{BC}=\mathrm{EF}$.

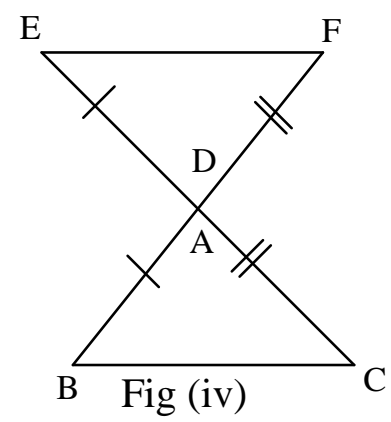

However, the figure had yielded a definite way of linking the contending sides BC, EF. After some weeks of studying the pattern, it became clear to the researcher that appeal to higher mathematics may not be the way out. The juggling experiment continued until one faithful day while the researcher was sitting alone in his sitting room and looking with much concentration on the superimposed triangles, $\triangle \mathrm{DEF}$ on $\triangle \mathrm{ABC}$ he rotated $\triangle \mathrm{DEF}$ by $180^{\circ}$ over A and was struck by the pattern of the figure that emerged, fig(v).

Here again because $<\mathrm{A}=<\mathrm{D}$ and are vertically opposite angles, therefore $\mathrm{BE}, \mathrm{CF}$ are straight lines. In addition, the pairs of corresponding sides have been aligned. Indeed the coincident point of A and D was now a point of bisection of $\mathrm{BE}$ and $\mathrm{CF}$. It was immediately clear to the researcher that this was where all the efforts of a couple of months was leading. For, by joining BF, EC, the resulting quadrilateral becomes a parallelogram by a geometric theorem (if the diagonals of a quadrilateral bisect each other, the quadrilateral is a parallelogram) and hence $\mathrm{BC}=\mathrm{EF}$. The researcher however did not follow that line of proof. Looking at this rather mysterious figure, fig(v), closely showed that the contraption it represents is the cross section of a double cone. This is the source of the title of this research.

Clearly what the researcher had succeeded in doing was that he had compounded the two triangles to yield the cross section of a double cone. It turned out that this was the "hidden" secret of the proof. 


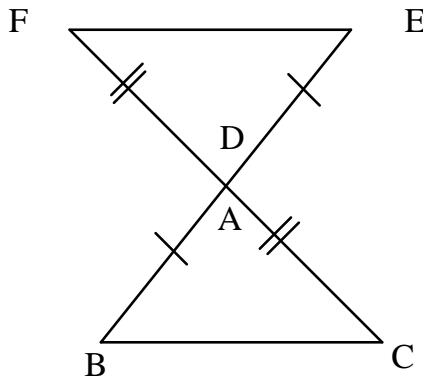

Fig (v)

\section{The Proof}

For the proof of the side angle side theorem (SAS) we need:

(1) The Axiom of Movement

(2) The Mid-Point theorem

1. Axiom of Movement

Any geometric figure may be moved from one place to another without changing its size or shape.

2. Mid-Point Theorem

The straight line joining the middle points of two sides of a triangle is parallel to the third side and equal to half of it.

\section{Theorem}

Two triangles are congruent if two sides and the included angle of one triangle are respectively equal to two sides and the included angle of the other.

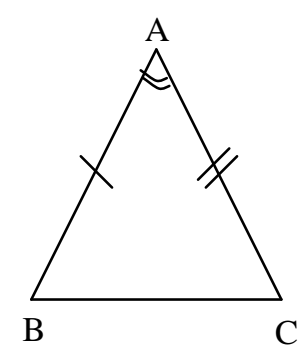

Fig (i)

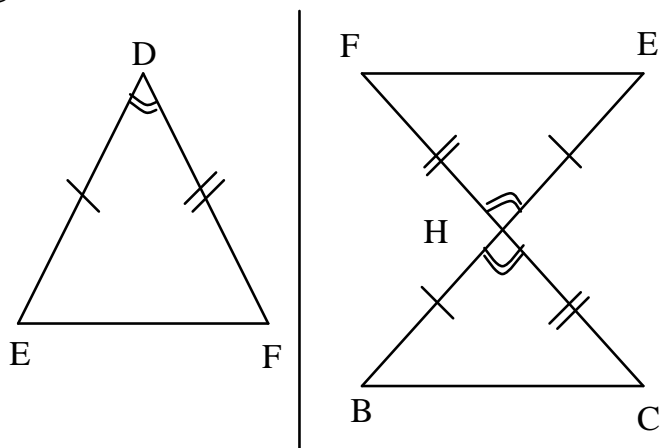

Fig (ii)

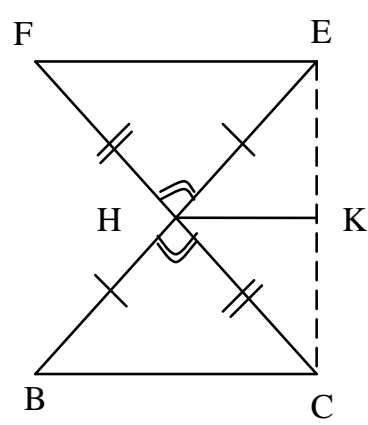

Fig (iii)

Given. $\mathrm{ABC}, \mathrm{DEF}$ are triangles such that.

$$
\begin{aligned}
\mathrm{AB} & =\mathrm{DE} \\
\mathrm{AC} & =\mathrm{DF} \\
<\mathrm{BAC} & =<\mathrm{EDF}
\end{aligned}
$$

To prove. $\triangle \mathrm{s} \mathrm{ABC}, \mathrm{DEF}$ are congruent

Construction: By the axiom permitting motion, apply $\triangle \mathrm{DEF}$ to $\triangle \mathrm{ABC}$ so that $\mathrm{D}$ falls on $\mathrm{A}$ and $\mathrm{E}$ falls on $\mathrm{B}$, and $\mathrm{EF}$ along $\mathrm{BC}$. Rotate $\triangle \mathrm{DEF}$ about $\mathrm{A}$ by $180^{\circ}$ to form the cross section of the double cone in fig.(ii). Join $\mathrm{EC}$ and, from the coincident point of $A$ and $D$ of the cross section, draw a line $\mathrm{HK}$ to bisect $\mathrm{EC}$ at $\mathrm{K}$, fig (iii). We write $\mathrm{H}$ $=(\mathrm{A} ; \mathrm{D})$ so that $\mathrm{H}$ refers to $\mathrm{A}$, or to $\mathrm{D}$ if we refer to $\triangle \mathrm{ABC}$, or $\triangle \mathrm{DEF}$.

The theorem will be proved if we can show that $\mathrm{BC}=\mathrm{EF}$.

Proof: $<\mathrm{BHC}=<\mathrm{EHF}$ (given)

But these are vertically opposite angles

$\therefore$ Lines $\mathrm{BE}, \mathrm{CF}$ are straight lines

In $\triangle \mathrm{BCE}, \quad \mathrm{BH}=\mathrm{EH}$ (given)

$$
\mathrm{CK}=\mathrm{EK} \text { (construction) }
$$

$\therefore$ HK bisects $\mathrm{BE}$ and $\mathrm{EC}$.

$\therefore$ In particular, $\mathrm{HK}=1 / 2 \mathrm{BC}$ (Mid-Point Theorem)

Similarly in $\triangle \mathrm{EFC}, \mathrm{HK}$ bisects $\mathrm{CF}$ and $\mathrm{CE}$ (Construction)

$\therefore \mathrm{HK}=1 / 2 \mathrm{EF}$ (Mid-Point Theorem)

$\therefore \mathrm{BC}=\mathrm{EF}$ (Things equal to the same thing are equal to each other)

$\therefore \Delta \mathrm{s}$ ABC, DEF are congruent

Q.E.D 


\section{Discussion}

From informal discussions with people on why this theorem had remained unproved for over two thousand years the researcher gleaned that many mathematicians must have tried to find a proof but made no headway and had to abandon it. Even Euclid himself who classified it as a theorem did not give an analytical proof of it. Thales who first used it to solve a surveying problem did not prove it even though he sacrificed a bull to the Gods for proving that the angle inscribed in a semi-circle is $90^{\circ}$. Some opinion has it that possibly because the SAS was the first theorem of congruence of triangles, there was no theorem before it with which to prove it. History has it that the forceful personality, mystic, philosopher and mathematician by the name of Pythagoras of the famous Pythagoras Theorem had banned his followers from divulging mathematical secrets. Could the proof of SAS have been caught up in that ban? All these did not discourage this researcher particularly since it was of utmost importance that students should be well acquainted with analytical methods of proof. From the beginning of this research work the researcher was very clear, profiting from the superposition method and the data of the theorem, that what was in doubt was whether the remaining pair of sides of the two triangles were equal. Hence the first step was to find how to link the two corresponding sides of the triangles. This was made possible by the axiom of movement stated earlier.

It enabled the movement and juggling of the two triangles leading to the first figure, fig(iv) where the two sides were linked. The figure could however not work for the proof of the theorem because, as it turned out, the pairs of the given corresponding sides were not aligned. However, the second figure, fig(v) obtained by rotating $\triangle \mathrm{DEF}$ about $\mathrm{A}$ by $180^{\circ}$ had the corresponding sides aligned.

It must be noted that the 'key' to our method of proof of the theorem is the axiom of movement while the 'secret' of the proof is the contraption of the two triangles described here as the cross section of a double cone. These two facts, the 'key' and the 'secret' it unlocked may have eluded past and even modern mathematicians. It must be remarked that the requirement that the lines $\mathrm{BE}, \mathrm{CF}$ or the linking lines $\mathrm{BE}$ and $\mathrm{CF}$ be straight lines is rigid. Hence the need to ensure that only equal angles were paired at the coincident point $\mathrm{H}$ of A and $\mathrm{D}$. The rotation by $180^{\circ}$ ensured that corresponding pairs of equal sides were aligned.

\section{Conclusion and Recommendation}

This research has shown that the elusive SAS (side angle side) theorem of congruence of triangles can be proved analytically. Indeed same goes for the other congruence theorems of triangles by applying, mutatis mutandis, the data for each theorem on the cross section of a double cone with the appropriate construction. This researcher has already succeeded in doing so. This research has also given the world of mathematics an entirely new and more uniform procedure for proving the congruence theorem of triangles using the cross section of a double cone. Now that the congruence theorems have been proved, it is strongly recommended that the method of superposition be relegated to the primary school level, while the secondary and higher levels of education should ensure and emphasize that the analytical method of proof is adopted. According to I. Stewart and D. Tall in Foundations of Mathematics (1977), "To show a student the finished edifice, without the scaffolding required for its construction, is to deprive him of the very facilities which are essential if he is to construct mathematical ideas of his own".

The analytical procedure ensures better understanding of the theorems and prepares the students for higher studies. New books at the secondary and tertiary levels should adopt the analytical method of proof.

\section{P.S}

A personal note for the records

When this researcher for the first time concluded the proof of the SAS theorem, a cracking sound rang through the right side of his head like something forced through a barrier causing the researcher to jump up to his feet with a start. He immediately felt a sharp headache on the left side of his forehead which forced him to go for paracetamol tablets which he swallowed with water from his nearby water dispenser. As he was all alone in the flat he decided to go outside his house to be sure he was alright. While outside he continuously but involuntarily nodded his head indicating that indeed he had proved the theorem. Since that day an ache he usually experienced as if a kink was disturbing the flow of fluid on the right side of his head disappeared. Hence the description of the hidden figure as mysterious. 


\section{Theorem}

Two triangles are congruent if two angles and a side of one are respectively equal to two angles and aside of the other.

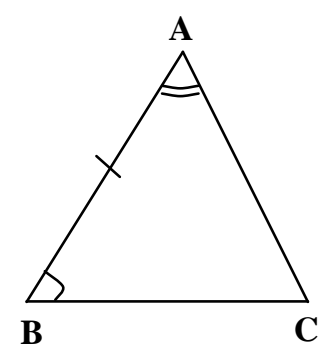

Fig. (i)

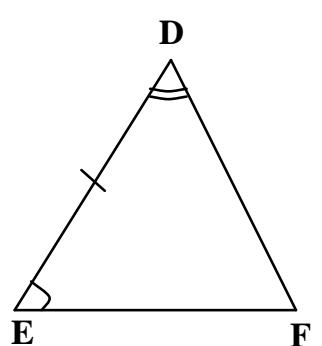

$\mathbf{E}$

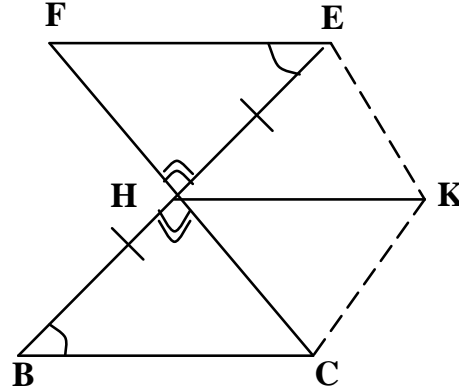

Fig. (ii)

Given. $\triangle \mathrm{s} A B C, \mathrm{DEF}$ are such that

$$
\begin{aligned}
<\mathrm{ABC} & =<\mathrm{DEF} \\
<\mathrm{BAC} & =<\mathrm{EDF} \\
\mathrm{AB} & =\mathrm{DE}
\end{aligned}
$$

To prove. $\triangle \mathrm{s} \mathrm{ABC}, \mathrm{DEF}$ are congruent

Construction. By axiom permitting motion, apply $\triangle \mathrm{DEF}$ to $\triangle \mathrm{ABC}$ so that $\mathrm{D}$ falls on $\mathrm{A}$ and $\mathrm{E}$ falls on $\mathrm{B}$ and $\mathrm{EF}$ along BC. Rotate $\triangle \mathrm{DEF}$ about $\mathrm{A}$ by $180^{\circ}$. From the coincident point $\mathrm{H}$ of $\mathrm{A}$ and $\mathrm{D}$ of the cross section of the double cone so formed, draw HK equal and parallel to BC. Join EK, CK, see fig (ii). H = (A;D) by our convention.

Proof; $<\mathrm{BHC}=<\mathrm{EHF}$ (given), but these are vertically opposite $<\mathrm{s}$.

$\therefore \mathrm{BE}, \mathrm{CF}$ are straight lines

$<\mathrm{HBC}=<\mathrm{HEF}$ (given). But these are alternate $<\mathrm{s}$.

$\therefore \mathrm{BC} / / \mathrm{EF}$, but $\mathrm{BC} / / \mathrm{HK}$ (construction)

$\therefore \mathrm{HK} / / \mathrm{EF}$

By construction HBCK is a parm (pair of opposite Sides equal and //)

$\therefore \mathrm{HB}=\mathrm{CK}$ and $\mathrm{HB} / / \mathrm{CK}$ i.e. $\mathrm{EB} / / \mathrm{CK}$. But $\mathrm{HB}=\mathrm{HE}$ (given)

$\therefore \mathrm{HE}=\mathrm{CK}$

$\therefore$ HCKE is a parm (pair of opposite sides equal and //)

$\therefore$ HC//EK i.e. FC//EK. But HK//EF (proved)

$\therefore$ HKEF is a parm

$\therefore \mathrm{HK}=\mathrm{EF}$, but $\mathrm{HK}=\mathrm{BC}$ (construction)

$\therefore \mathrm{BC}=\mathrm{EF}$

In $\triangle \mathrm{s} A B C, D E F$

$\mathrm{BC}=\mathrm{EF}$ (proved)

$\mathrm{AB}=\mathrm{DE}$ (given)

$<\mathrm{ABC}=<\mathrm{DEF}$ (given)

$\therefore \triangle \mathrm{s} \mathrm{ABC}, \mathrm{DEF}$ are congruent SAS 


\section{Theorem}

Two right-angled triangles are congruent if the hypotenuse and a side of one triangle are respectively equal to the hypotenuse and a side of the other.

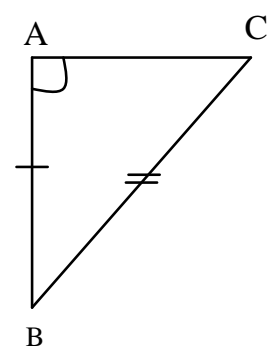

Fig. (i)

Given. $\triangle \mathrm{s} A B C$, DEF are right-angled

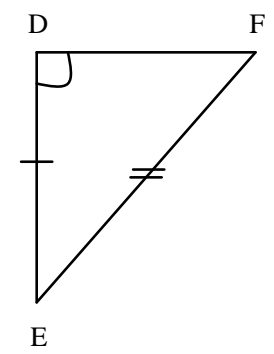

at $\mathrm{A}$ and $\mathrm{D}$

Hypotenuse $\mathrm{BC}=$ Hypotenuse $\mathrm{EF}$

$$
\mathrm{AB}=\mathrm{DE}
$$

To prove. $\triangle \mathrm{s} \mathrm{ABC}, \mathrm{DEF}$ are congruent

Construction. By axiom permitting motion, apply $\triangle \mathrm{DEF}$ to $\triangle \mathrm{ABC}$ so that $\mathrm{D}$ falls on $\mathrm{A}$ and $\mathrm{E}$ falls on $\mathrm{B}$, and $\mathrm{DF}$ along $\mathrm{AC}$. Rotate $\triangle \mathrm{DEF}$ about $\mathrm{A}$ by $180^{\circ}$. Join $\mathrm{EC}$ as shown in fig (ii), label the coincident point $\mathrm{A}, \mathrm{D}$ of the cross section of the double cone so formed as $\mathrm{H}=(\mathrm{A} ; \mathrm{D})$ so that $\mathrm{H}$ refers to $\mathrm{A}$, or to $\mathrm{D}$ if we refer to $\triangle \mathrm{ABC}$, or $\triangle \mathrm{DEF}$. Join EC.

Proof. In $\triangle \mathrm{s} \mathrm{BHC}, \mathrm{EHF}$,

$<\mathrm{BHC}=<\mathrm{EHF}=1 \mathrm{rt} .<$ (given)

But these are vertically opposite angles

$\therefore \mathrm{BE}, \mathrm{CF}$ are straight lines

$\therefore<\mathrm{EHC}=1$ rt. $<$

In $\triangle \mathrm{s} H B C, \mathrm{HEC}$

$\mathrm{HB}=\mathrm{HE}$ (given)

$\mathrm{HC}$ is common

$<\mathrm{BHC}=<\mathrm{EHC}(\mathrm{rt} .<\mathrm{s})$

$\therefore \Delta \mathrm{s} \mathrm{HBC}, \mathrm{HEC}$ are congruent (SAS)

In particular, $\angle \mathrm{HCB}=\angle \mathrm{HCE}$ and $\mathrm{BC}=\mathrm{EC}$

But $\mathrm{BC}=\mathrm{EF}$ (given)

$\therefore \mathrm{EC}=\mathrm{EF}$

$\therefore \triangle \mathrm{EFC}$ is isosceles

$\therefore<\mathrm{HCE}=<\mathrm{HFE}($ base $<\mathrm{s}$ of isos $\Delta$ )

But $<\mathrm{HCE}=<\mathrm{HCB}$ (proved)

$\therefore<\mathrm{HCB}=<\mathrm{HFE}$, i.e. $<\mathrm{ACB}=<\mathrm{DFE}(\mathrm{H}=\mathrm{A} ; \mathrm{D})$

In $\triangle \mathrm{s} A B C, \mathrm{DEF}$

$\mathrm{BC}=\mathrm{EF}$ (given)

$<\mathrm{BAC}=<\mathrm{EDF}$ (given)

$<\mathrm{ACB}=<\mathrm{DFE}$ (proved)

$\therefore \Delta \mathrm{s}$ ABC, DEF are congruent (AAS)

Q.E.D 


\section{Theorem}

If in two triangles the three sides of the one are respectively equal to the three sides of the other, the triangles are congruent.

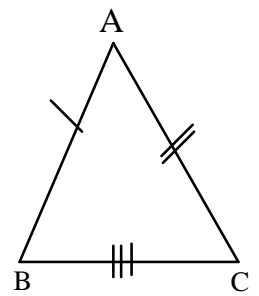

Fig (i)

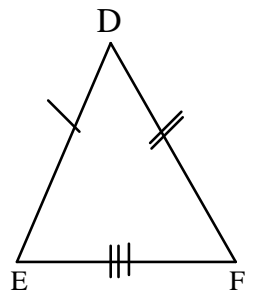

E

Given. $\mathrm{ABC}, \mathrm{DEF}$ are $\triangle \mathrm{s}$ in which

$\mathrm{AB}=\mathrm{DE}, \mathrm{BC}=\mathrm{EF}, \mathrm{AC}=\mathrm{DF}$

To prove. The $\triangle \mathrm{s} A B C, D E F$ are congruent

Construction. At $\mathrm{H}$ extend $\mathrm{BH}, \mathrm{CH}$ to $\mathrm{E}^{1}, \mathrm{~F}^{1}$ such that

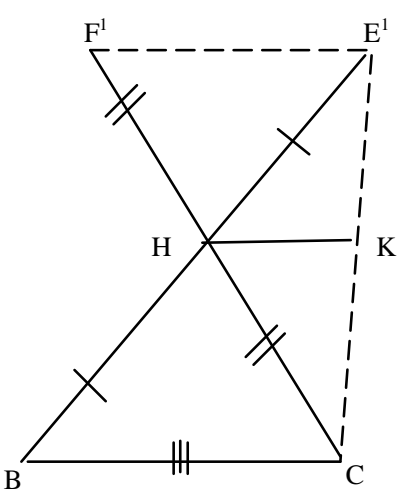

Fig (ii)

$H E^{1}=D E, H F^{1}=D F$. Join $E^{1} F^{1}$. Also join $E^{1} C$. From $H$ draw $H K$ to bisect $E^{1} C$ at $K$, fig (ii).

Proof. In $\triangle \mathrm{BE}^{1} \mathrm{C}$, $\mathrm{HK}$ bisects $\mathrm{BE}^{1}$ and $\mathrm{E}^{1} \mathrm{C}$ (construction)

$\therefore \mathrm{HK} / / \mathrm{BC}$ and $\mathrm{HK}=1 / 2 \mathrm{BC}$ (Mid-Point Theorem).

Similarly in $\Delta \mathrm{E}^{1} \mathrm{~F}^{1} \mathrm{C}$, $\mathrm{HK}$ bisects $\mathrm{E}^{1} \mathrm{C}$ and $\mathrm{CF}^{1}$

$\therefore \mathrm{HK} / / \mathrm{E}^{1} \mathrm{~F}^{1}$ and $\mathrm{HK}=1 / 2 \mathrm{E}^{1} \mathrm{~F}^{1}$

Since $\mathrm{HK} / / \mathrm{BC}$ and $\mathrm{HK} / / \mathrm{E}^{1} \mathrm{~F}^{1} \therefore \mathrm{BC} / / \mathrm{E}^{1} \mathrm{~F}^{1}$

$\therefore<\mathrm{E}^{1} \mathrm{BC}=\left\langle\mathrm{BE}^{1} \mathrm{~F}^{1}\right.$ (alternative $<$ s) i.e. $<\mathrm{HBC}=<\mathrm{HE}^{1} \mathrm{~F}^{1}$

Also $\mathrm{HK}=1 / 2 \mathrm{BC}$ and $\mathrm{HK}=1 / 2 \mathrm{E}^{1} \mathrm{~F}^{1}$ (proved)

$\therefore \mathrm{BC}=\mathrm{E}^{1} \mathrm{~F}^{1}$. But $\mathrm{BC}=\mathrm{EF}$ (given)

$\therefore \mathrm{E}^{1} \mathrm{~F}^{1}=\mathrm{EF}$, i.e. $\mathrm{E}^{1}$ coincides with $\mathrm{E}$ and $\mathrm{F}^{1}$ coincides with $\mathrm{F}$

$\therefore<\mathrm{B}=<\mathrm{E}$

In $\triangle \mathrm{s} A B C, \mathrm{DEF}$

$$
\begin{aligned}
& \mathrm{AB}=\mathrm{DE} \text { (given) } \\
& \mathrm{BC}=\mathrm{EF} \text { (given) } \\
& <\mathrm{ABC}=<\mathrm{DEF} \text { (proved) }
\end{aligned}
$$

$\therefore \triangle \mathrm{s} \mathrm{ABC}, \mathrm{DEF}$ are congruent, SAS.

Q.E.D

\section{References}

[1]. Abbott, P. ( 1988). Teach Yourself Geometry. Hodder and Stoughton Educational, Great Britain.

[2]. Bass, E. et al (1988). Geometry, Prentice-Hall, Inc. New Jersey

[3]. Bergamini, D. (1970), Mathematics, Time-Life Books, New York

[4]. Bouwsma, W. D. (1972), Geometry for Teachers, McMillan Company, New York.

[5]. Durell C. V. (1961), A New Geometry for Schools, G. Bell and Sons Ltd, London.

[6]. Hogben L. (1967), Mathematics for the Million, Richard Clay and Company Ltd, Great Britain.

[7]. Miller D. (1942), Popular Mathematics, Cardward - Mclaun, New York.

[8]. Skolink D. (1950), Dynamic Plane Geometry, D. Van Nostrand Company, Inc. Princeton, New Jersey.

[9]. Stewart I. and Tall D. (1977), Foundations of Mathematics, Oxford University Press, Great Britain.

[10]. Todhunter I. (Editor), (1961), Euclid's Elements, J. M. Dent \& Sons Ltd London. 